\title{
STUDI KONDISI UDARA DI ATAS GUNUNGAPI BATUR DENGAN MENGGUNAKAN GPS
}

\author{
Wedyanto Kuntjoro 1), Dudy Darmawan ${ }^{1)}$, Hasanuddin Z. Abidin 1), F. Kimata ${ }^{2)}$ \\ Mipi A. Kusuma 1), M. Hendrasto ${ }^{3)}$, Oni K. Suganda ${ }^{3)}$
}

1) Department of Geodetic Engineering, Institute of Technology Bandung (ITB), J1. Ganesha 10, Bandung 40132, e-mail: wedyanto@gd.itb.ac.id

2) Research Center for Seismology and Volcanology Nagoya University - Japan

3) Volcanological Survey of Indonesia (VSI), J1. Diponegoro 57, Bandung 40122

\begin{abstract}
ABSTRAK
Gunung Batur merupakan gunungapi yang masih aktif. Pemantauan kondisi udara di atasnya sudah tentu sangat diperlukan untuk antara lain dalam mitigasi, temasuk usaha preventif, bencana akibat letusa-letusan yang terjadi; dalam menentukan faktor lingkungan udara yang berpengaruh pada ekosistem di sekitar gn. Batur. Untuk itulah, aplikasi GPS mulai diperkenalkan kedalam usaha seperti ini dimana secara khusus melakukan ekstraksi nilai delay gelombang elektromagnetik pada atmosfir, khususnya troposfir yang disebut sebagai Zenith Tropospheric Delay (ZTD). Bias ZTD terbagi ke dalam dua buah komponen yaitu komponen wet (ZTDw) dan dry $\left(Z T D_{D}\right) . Z T D_{w}$ selanjutnya dianalisa untuk keperluan pemantauan udara di atas permukaan titik-titik amat. Pengamatan pada tanggal 14 dan $17 \mathrm{Mei}$ 1999 dari 11(sebelas) titik-amat GPS menghasilkan: Besar ZTDw maksimum, dari pengamatan tanggal 14 (hari-1) dan 17(hari-2) Mei 1999, mencapai $18 \mathrm{~cm}$. Terjadi kondisi anomali kandungan di udara pada pk.16:00-17:00 dan anomali peningkatan kandungan udara pada pk.14:0015:00 di hari-1. Pada hari-2, perubahan udara terjadi saat pk.13:00-14:00 dan terjadi anomali peningkatan kandungan udara saat pk.16:00-17:00. Dengan mengamati hasil-hasil, aliran udara di atas gn.Batur terdiri dari dua alur. Pertama, alur barat-timur mendominasi dan yang kedua adalah alur baratlaut-tenggara.
\end{abstract}

\section{PENDAhuluan}

Pada dasarnya teknologi satelit GPS (Global Positioning System) dirancang untuk menentukan posisi titik-titik di permukaan bumi dengan spektrum ketelitian yang bisa diperoleh mulai dari level $\boldsymbol{d} \boldsymbol{m}$ sampai $\mathbf{m m}$. Oleh karena itu teknologi ini bisa digunakan pada bidang aplikasi dengan spektrum yang luas pula, mulai dari aplikasi yang hanya membutuhkan ketelitian menengah (kepentingan rekayasa dan geoteknik) hingga aplikasi yang membutuhkan ketelitian yang sangat tinggi (kepentingan penelitian, seperti pemantauan geodinamika bumi).

Ketika sinyal yang dipancarkan oleh satelit GPS merambat menuju antena receiver GPS, sinyal tersebut akan melalui lapisan atmosfir. Lapisan atmosfir ini akan mempengaruhi cepat rambat sinyal GPS sehingga jarak yang dihitung akan memberikan nilai yang salah. Lapisan atmosfir ini terbagi kedalam dua lapisan utama yaitu lapisan ionosfir dan troposfir, Dalam bidang kajian ilmu GPS, lapisan ionosfir dan troposfir ini menjadi bias tersendiri yang harus direduksi sebelum menentukan posisi akhir sebuah titik.

Diantara kedua bias tersebut, bias akibat lapisan troposfir memberikan efek yang cukup signifikan dalam penentuan posisi GPS, dalam hal ini efek tersebut akan mempengaruhi komponen tinggi GPS. Terdapat beberapa cara untuk mereduksi bias akibat lapisan troposfir ini antara lain dengan cara pemodelan dan pengestimasian. Kedua cara 
tersebut pada intinya adalah menentukan besarnya penyimpangan jarak dari satelit GPS ke antena receiver GPS sebagai akibat perlambatan waktu tempuh selama sinyal melewati lapisan troposfir. Penyimpangan jarak akibat perlambatan waktu tempuh sinyal GPS umumnya disebut dengan Zenith Tropospheric Delay (ZTD). Harga ZTD ini yang kemudian akan dijadikan sebagai faktor koreksi untuk menentukan jarak satelit GPS ke antena receiver GPS. Selanjutnya, besaran ZTD tersebut bisa digunakan untuk mengkarakterisir kondisi troposfir disekitar daerah pengamatan GPS. Metode ini bisa disebut sebagai metode inversi dalam penggunaan GPS.

\section{DASAR TEORI}

Dengan mengasumsikan bias ionosfir tidak memberikan efek yg terlalu signifikan pada jaring GPS berukuran kecil, persamaan dasar double-difference data fase untuk menghitung jarak satelit GPS ke antena receiver GPS menjadi sebagai berikut :

$$
L_{k l}^{i j}=\rho_{k l}^{i j}+Z T D+n_{k l}^{i j}
$$

dimana $L$ adalah jarak satelit GPS ke antena receiver GPS yang dianggap benar, $\rho$ merupakan jarak satelit GPS ke antena receiver GPS yang terukur, $n$ merupakan bias ambiguitas dan ZTD adalah bias delay di troposfir.

Terdapat beberapa cara untuk memperoleh harga koreksi ZTD yaitu dengan cara diestimasi dengan menggunakan proses Kalman filtering dan menggunakan pemodelan. Pada makalah ini, untuk memperoleh harga koreksi ZTD tersebut dilakukan dengan cara pemodelan dan kemudian hasil dari model terebut dianggap sebagai hasil apriori yang pada tahap selanjutnya diestimasi dengan menggunakan proses Kalman filtering. Model yang digunakan adalah model yang diajukan oleh Saastamoinen, dengan formula sebagai berikut :

$$
Z T D=\frac{0.002277}{\operatorname{Cos} Z}\left[P+\left(\frac{1255}{T}+0.05\right) e-\tan ^{2} Z\right],
$$

harga $\boldsymbol{e}$ menyatakan tekanan parsial dari kelembaban udara. Nilai tekanan, temperatur dan kelembaban bisa diturunkan dari model atmosfir standar yang diukur berdasarkan ketingian[Saastamoinen, 1963 dalam Wedyanto et al 1999a] :

$$
\begin{aligned}
& P=P_{0}\left(1-0.000226\left(h-h_{0}\right)\right)^{5.225} \\
& T=T_{0}-0.0065\left(h-h_{0}\right) \\
& H=H_{0} \cdot e^{-0.0006396\left(h-h_{0}\right)}
\end{aligned}
$$

dengan nilai $h_{o}, T_{0}, P_{0}, H_{0}$ ditentukan berdasarkan kondisi di titik yang diamati.

Bias ZTD terbagi ke dalam dua buah kompnen yaitu komponen wet $\left(\mathrm{ZTD}_{\mathrm{w}}\right)$ dan dry $\left(Z T D_{D}\right)$. Untuk menentukan komponen dry bisa digunakan dengan menggunakan model hidrostatik yang berkorelasi terbalik dengan faktor ketinggian suatu titik/tempat.

\section{PENGAMATAN GPS}

Pada makalah ini data GPS yang digunakan adalah data pengamatan GPS untuk pemantauan deformasi gunungapi Batur pada tanggal 14 dan 17 Mei 1999. Sebanyak sebelas titik EDM yang dipasang di sekitar kaldera luar dan kawah gunungapi Batur diamati dengan menggunakan enam receiver GPS tipe geodetik dual frekuensi selama 10-11 jam setiap 30 detik pada sudut elevasi 15 derajat. Sebaran titik-titik GPS tersebut ditunjukan pada gambar 1a berikut. Jaring GPS dibuat radial terhadap titik DB01. 
Pengolahan data GPS untuk menentukan nilai ZTD dilakukan dengan menggunakan perangkat lunak ilmiah Bernese 4.2 versi linux, dimana prosedur pengolahan datanya di jelaskan sebagai berikut. Pada makalah ini, untuk menghitung harga koreksi ZTD setiap titik-titik GPS, relatif terhadap titik ikat, data fase double-difference L1 digunakan sebagai data pengamatan. Kemudian informasi orbit presisi digunakan secara bersamaan dengan informasi parameter kutub yang dikeluarkan oleh Buletin A IERS (International Earth Rotation Service). Harga apriori koreksi ZTD diperoleh dengan menggunakan model sastamoinen, kemudian dilanjutkan dengan mengestimasi harga akhir dari koreksi ZTD tersebut dengan menggunakan proses Kalman filtering. Pengkoreksian harga ZTD ini dilakukan setiap 1 jam. Hasil akhir dari pengolahan data GPS ini adalah time series dari harga-harga koreksi ZTD setiap jam untuk semua titiktitik GPS yang tersebar di gunungapi Batur.

Harada et.al [1998] mengemukakan beberapa hubungan antara ketinggian topografi dengan delay hidrostatik. Selanjutnya untuk kasus gn. Batur ini bisa dilihat pada Gambar 1b dimana untuk lokasi dengan ketinggian antara $1080 \mathrm{~m}$ sampai $1200 \mathrm{~m}$ mengalami delay hidrostatik sebesar $193-198 \mathrm{~cm}$. Terlihat semakin rendah suatu lokasi akan semakin tinggi delay hidrostatiknya. Model hidrostatik digunakan untuk menentukan komponen dry dan kemudian mengkoreksikannya kepada nilai ZTD sehingga diperoleh time series nilai komponen wet $\left(\mathrm{ZTD}_{\mathrm{w}}\right)$. Dalam hasil berikut akan difokuskan pada hasil $Z_{\mathrm{TT}}$ w karena sifatnya yang tergantung pada kondisi penguapan dan troposfir lokal.

\section{HASIL-HASIL}

Semua data diproses untuk selang waktu 1 (satu) jam pada data pengamatan tanggal 14 dan 17 Mei tersebut. Proses ini akan menghasilkan nilai $Z_{T} D_{w}$ pada setiap titik pengamatannya. Secara spasial dan urut waktu hasil perolehan $Z_{T} D_{\mathrm{w}}$ pada tanggal 14 Mei 1999 (hari-1) dapat dilihat pada Gambar 2 dan pada tanggal 17 Mei 1999 (hari-2) terlihat pada Gambar 3.

Hasil pada hari-1 memperlihatkan $Z \mathrm{TD}_{\mathrm{w}}$ terendah sebesar $9 \mathrm{~cm}$ dan terbesar mencapai $18 \mathrm{~cm}$. Dari Tabel 1, terlihat pada hari-1 selang (selisih nilai tertinggi dan terendah) $Z \mathrm{TD}_{\mathrm{w}}$ terjadi pada pk.11:00-12:00. Kemungkinan ini bisa terjadi karena pada tengah hari (at noon) peristiwa penguapan umumnya sangat besar. Namun demikian, pada pk. 14:00-15:00 terjadi kenaikan jumlah $Z \mathrm{TD}_{\mathrm{w}}$ dibandingkan pada saat sebelumnya, pk.12:00 sampai pk.14:00. Kemungkinan proses pemanasan oleh matahari tentunya tidak mungkin terjadi lebih besar dibandingkan saat sebelumnya. Kemungkinan terbesar adalah di atas gn. Batur terjadi: (1) Kandungan awan meningkat, atau (2) Kandungan uap air bertambah yang disebabkan oleh penguapan lokal secara drastis. Kejadian (1) ditunjukkan dengan korelasi positif antara curah hujan dan wet delay dalam Wedyanto et.al [1999b].

Aktivitas ini sepertinya tidak nampak pada hari-2, dimana selang $Z_{T} D_{\mathrm{w}}$ hampir konstan. Namun demikian, terlihat penguapan akibat pemanasan matahari terjadi lebih cepat yaitu menjelang pk.11.00 karena $Z Z_{\mathrm{w}}$ sebesar $17 \mathrm{~cm}$ hampir mendominasi seluruh area. Kondisi ini berubah menurun dimulai pada pk.11:00 sampai pk.13:00. Selanjutnya terjadi perubahan kondisi $Z \mathrm{ZTD}_{\mathrm{w}}$ pada pk.13:00-14:00, yaitu pada saat terjadinya peningkatan $Z T D_{w}$ di wilayah selatan area. $Z \mathrm{TD}_{\mathrm{w}}$ di wilayah selatan itu menurun pada pk.14:00 sampai dengan pk.16:00 dengan kisaran distribusi sebesar $14-18 \mathrm{~cm}$.

Kondisi ini berubah tiba-tiba pada pk.16:00-17:00 dimana nilai maksimum $17 \mathrm{~cm}$ mendominasi seluruh wilayah kecuali pada wilayah timurlaut. Peristiwa terakhir ini tidak sesuai dengan kondisi normal karena penguapan akibat pemanasan matahari sudah jauh berkurang. Selain itu, kandungan awan pun tidak mungkin berpengaruh maksimum atas nilai $Z_{\mathrm{TD}}$. 
Kemudian, dengan melihat gradasi atau perubahan $\mathrm{ZTD}_{\mathrm{w}}$ dalam arah barat-timur terlihat mayoritas terjadi pada hampir semua saat di hari-1 dan hari-2, perubahan massa udara berlangsung pada alur barat-timur. Situasi ini didukung secara kuat dengan melihat Gambar 2 dimana pada pk.15:00-16:00 kondisi di bagian barat merambat menuju timur yang hasilnya bisa dilihat pada hasil saat berikutnya, pk.16:00-17:00. Apabila alur barat-timur tidak terjadi hanya ada satu kemungkinan lain yakni alur baratlaut-tenggara, -- pk.11:00 sampaidengan pk.14:00 pada hari-1 dan pk.15:00 sampai dengan pk.17:00 pada hari-2--.

Tabel 1. Besar Selang ZTD ${ }_{\mathrm{w}}$ pada Hari-1 dan Hari-2 tahun 1999.

\begin{tabular}{|c|c|c|}
\hline Saat (WIB) & $\begin{array}{c}\text { Selang ZTD } \\
\text { (cm) }\end{array}$ & $\begin{array}{c}\text { Selang ZTD } 14 \text { Mei } \\
\text { (cm) } 14\end{array}$ \\
\hline $10: 00-11: 00$ & $9-14$ & $5-18$ \\
\hline $11: 00-12: 00$ & $9-18$ & $5-18$ \\
\hline $12: 00-13: 00$ & $9-15$ & $5-18$ \\
\hline $13: 00-14: 00$ & $10-15$ & $5-18$ \\
\hline $14: 00-15: 00$ & $9-17$ & $5-18$ \\
\hline $15: 00-16: 00$ & $9-15$ & $5-18$ \\
\hline $16: 00-17: 00$ & $11-17$ & $6-18$ \\
\hline
\end{tabular}

\section{KESIMPULAN}

Perolehan ZTD $_{\mathrm{w}}$ hasil pengamatan GPS dapat digunakan untuk melihat kondisi udara di atas permukaan gn. Batur. Besar $Z_{\mathrm{TT}}$ waksimum, dari pengamatan tanggal 14 (hari1) dan 17(hari-2) Mei 1999, mencapai $18 \mathrm{~cm}$. Terjadi kondisi anomali kandungan di udara pada pk.16:00-17:00 dan anomali

peningkatan kandungan udara pada pk.14:00-15:00 di hari-1. Pada hari-2, perubahan udara terjada saat pk.13:00-14:00 dan terjadi anomali peningkatan kandungan udara saat pk.16:00-17:00. Dengan mengamati hasil-hasil, aliran udara di atas gn.Batur terdiri dari dua alternatif alur. Alternatif pertama, alur barat-timur mendominasi dan alternatif kedua adalah alur baratlaut-tenggara.

\section{UCAPAN TERIMAKASIH}

Riset ini dapat terlaksana atas kerjasama antara Departemen Geodesi - FTSP -ITB, Direktorat Vulkanologi dan Research Center for Seismology and Volcanology Nagoya University - Japan. Terimakasih juga dialamatkan kepada para Mahasiswa yang telah membantu dalam survey lapangan. Ucapan khusus juga disampaikan kepada Observatori Batur.

\section{DAFTAR PUSTAKA}

Harada M, I. Naito, N. Mannoji, T. Tanaka, A simulation Study of GPS Positioning Errorr due to Atmospheric Delay, 90 ${ }^{\text {th }}$ Meeting Program and Abstract Geodetic Society of Japan,pp. 129-130, 1998.

Wedyanto Kuntjoro, M. A. Kusuma, I. Meilano, Penentuan Delay Gelombang Elektromagnetik di Troposfir dalam Studi Kasus gn. Guntur dan Sekitarnya, Laporan Penelitian DIK LP-ITB, 1999a.

Wedyanto Kuntjoro, H. Z. Abidin, J. Kahar, Z. L. Dupe, Sudono, T. Manik, Preliminary Study of GPS for Meteorology Towards Dense Site of Tropospheric Monitoring on Bandung Area, Proceeding of $2^{\text {nd }}$ International Conference on Science and Technology for Assessment of Global Climate Change and Its Impacts on Indonesian Maritime Continent,C3.1-3.3, 199b 

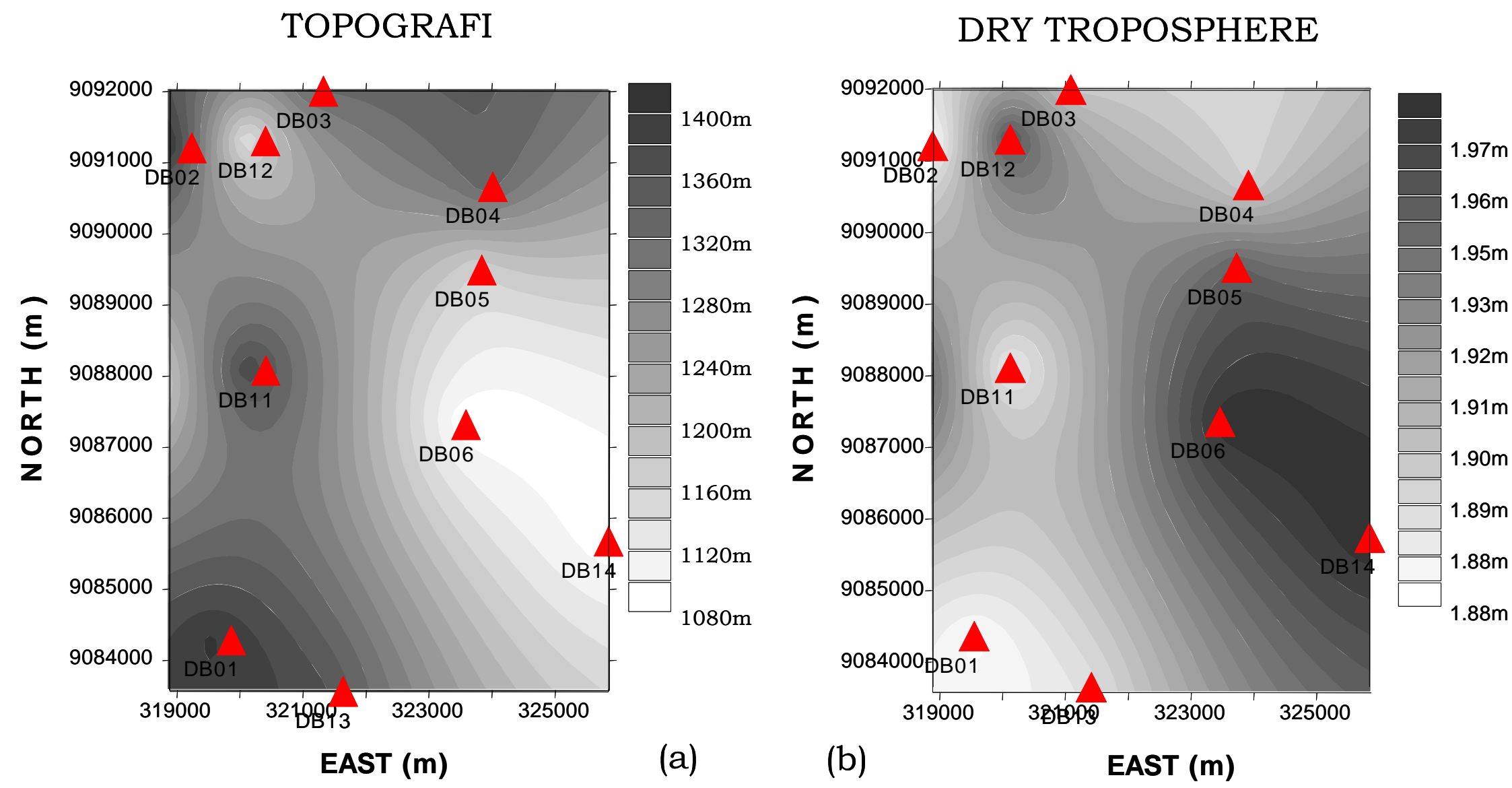

Gambar 1. (a). Kontur Topografi Lokasi Titik-titik Amat, dan

(b). Besar Delay-kering Troposfir di Atas Lokasi Pengamatan 


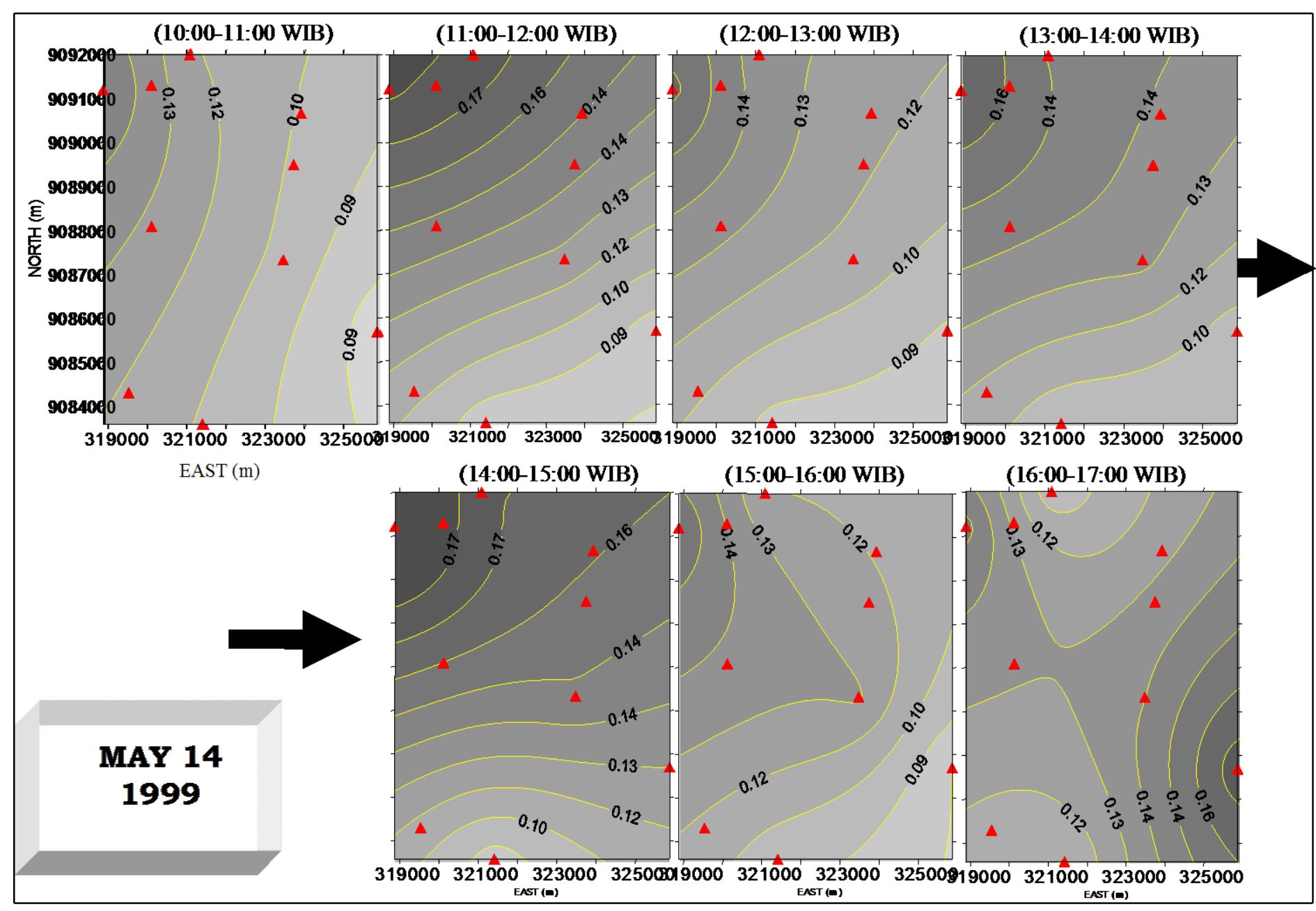

Gambar 2. Distribusi Kondisi Wet pada tanggal 14 Mei 1999 di gn. Batur untuk Setiap Jam Pengamatannya; nilai kontur dalam satuan meter; simbol segitiga merah menunjukkan titik-titik amat GPS. 


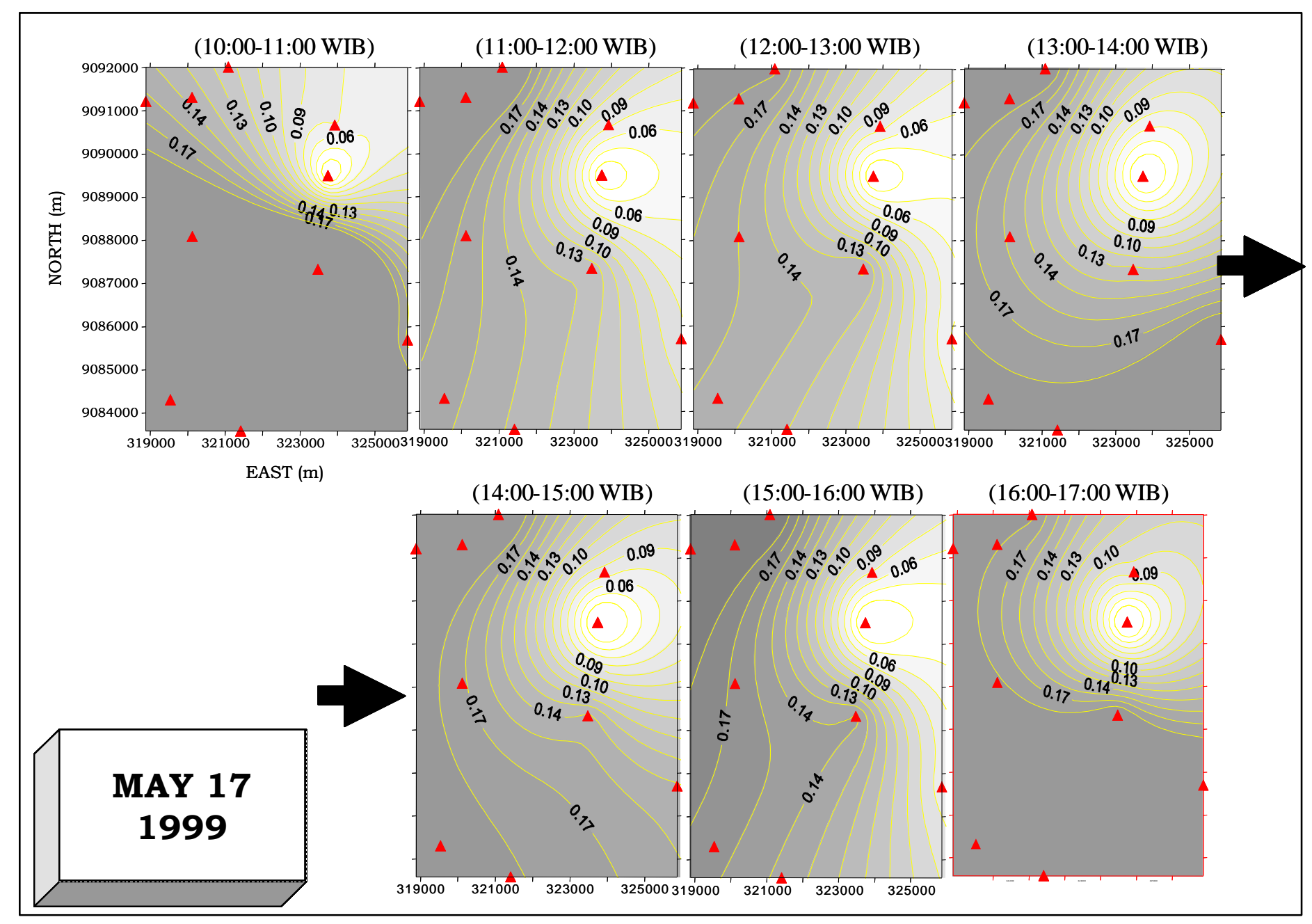

Gambar 3. Distribusi Kondisi Wet pada tanggal 17 Mei 1999 di gn. Batur untuk Setiap Jam Pengamatannya; nilai kontur dalam satuan meter; simbol segitiga merah menunjukkan titik-titik amat GPS 